\title{
Diagnosis and Management of Iatrogenic Hemobilia Secondary to Transjugular Intrahepatic Portosystemic Shunt Procedure
}

\author{
Gino Puntel ${ }^{1}$, Giovanni Puppini ${ }^{1}$, Simone Perandini ${ }^{1}$, Riccardo De Robertis ${ }^{1}$, Stefania Montemezzi ${ }^{1}$ \\ 1. Radiology, Azienda Ospedaliera Universitaria Integrata Verona, Verona, ITA
}

Corresponding author: Gino Puntel, gino.puntel@aovr.veneto.it

\begin{abstract}
A patient with end-stage liver disease and subsequent refractory ascites was treated with a transjugular intrahepatic portosystemic shunt (TIPS) procedure. The procedure was complicated by massive gastrointestinal hemorrhage with associated rettorragia. Computed tomography angiography (CT-A) was performed and revealed haemobilia due to an artero-biliary fistula between the right hepatic artery and an intrahepatic biliary branch. The patient underwent an attempt at percutaneous embolization. Bleeding was successfully stopped by the embolization of the fistula with coils.
\end{abstract}

Hemobilia is a rare cause of upper gastrointestinal bleeding with an increasing incidence due to the widespread use of invasive hepatobiliary procedures. Hemobilia is an uncommon complication of TIPS procedures. Nowadays, transcatheter embolization is the gold standard in the management of hemobilia.

Received 03/28/2020

Review began 04/05/2020 Review ended 04/06/2020 Published 04/10/2020

() Copyright 2020

Puntel et al. This is an open access article distributed under the terms of the Creative Commons Attribution License CC-BY 4.0., which permits unrestricted use, distribution, and reproduction in any medium, provided the original author and source are credited.
Categories: Emergency Medicine, Radiology, Gastroenterology Keywords: hepatology, interventional radiology, liver, transjugular intrahepatic portosystemic shunt, hemobilia, bleeding, complication, iatrogenic, endovascular, embolization

\section{Introduction}

Hemobilia occurs when a fistulous track forms between a hepatic vessel (hepatic artery or portal vein) and the intrahepatic biliary system or choledocus. The most frequent causes are iatrogenic after hepatobiliary system procedures and trauma [1-2]. The treatment of hemobilia is aimed at stopping the bleeding without interfering with the normal anatomy of the biliary and vascular structures. We report iatrogenic hemobilia as a complication of the transjugular intrahepatic portosystemic shunt (TIPS) procedure, which was successfully managed by transcatheter embolization [3].

\section{Case Presentation}

A 59-year-old man with alcohol abuse-related liver cirrhosis was treated for refractory ascites (model endstage liver disease (MELD) score 17) by means of a transjugular intrahepatic portosystemic shunt (TIPS) procedure. The procedure succeeded uneventfully, however, transient right hepatic artery branches opacification was observed during an attempt to position the Colapinto needle within the portal venous tree (Figure 1). 


\section{Cureus}

\section{FIGURE 1: Intraprocedural fluoroscopy}

Right hepatic artery branches' opacification (yellow star) was observed during an attempt to position the Colapinto needle (red arrow).

The patient was discharged from the operating room with no signs of complications. Two days later, a massive gastrointestinal hemorrhage with associated rettorragia occurred, leading to a significant decrease in hemoglobin (from $12 \mathrm{mg} / \mathrm{dl}$ to $6 \mathrm{mg} / \mathrm{dl}$ ); concomitant increased total bilirubin blood levels was detected (from $10 \mu \mathrm{mo} / \mathrm{L}$ to $290 \mu \mathrm{mo} / \mathrm{L}$ ). Computed tomography angiography (CT-A) was performed to assess haemobilia. Arterial phase images revealed contrast media filling of the biliary tree, the choledocus and the duodenum (Figure 2). 


\section{Cureus}

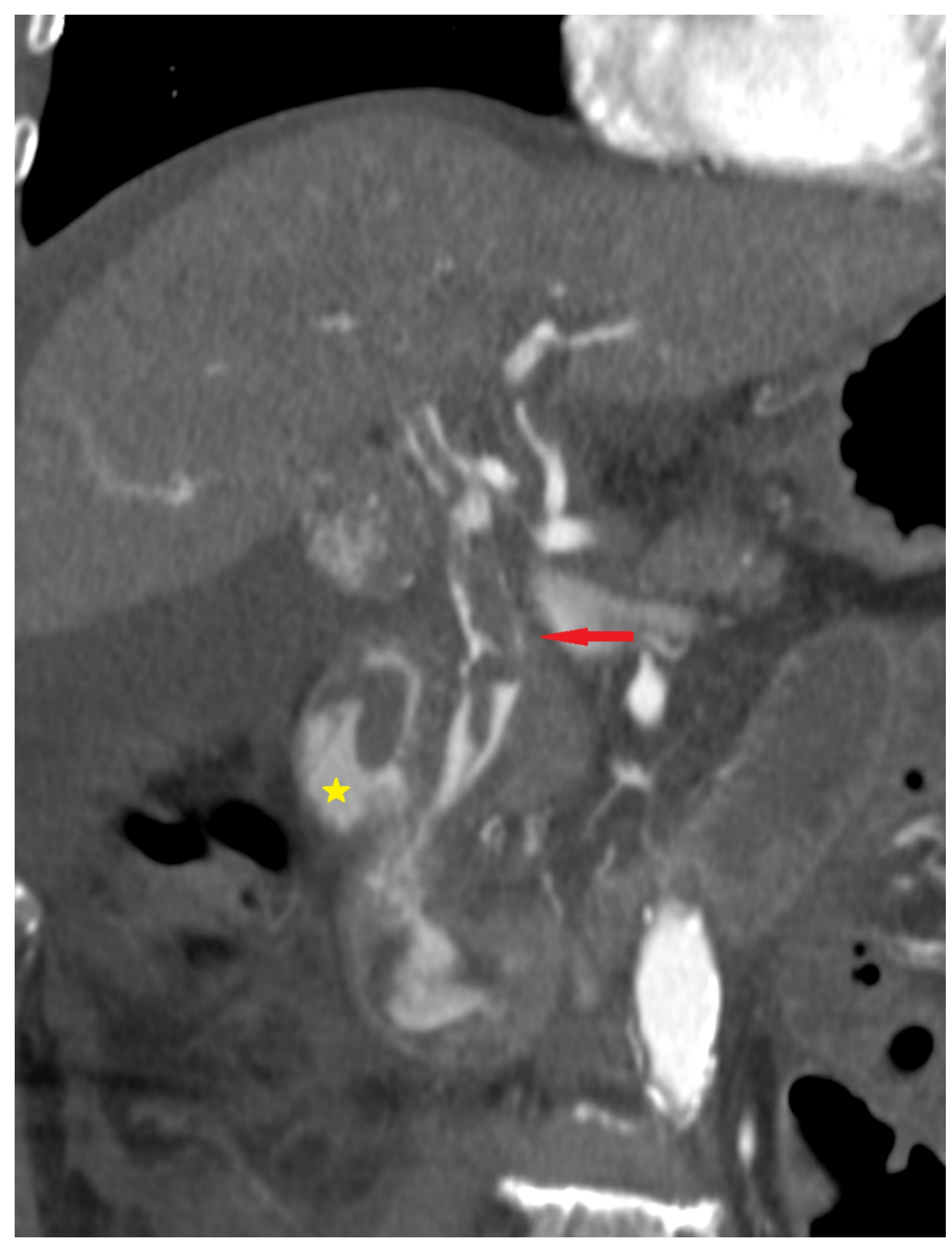

\section{FIGURE 2: CT angiography}

Arterial phase images revealed contrast media filling of the biliary tree, the choledocus (red arrow), and the duodenum (yellow star).

The patient underwent an attempt at percutaneous embolization. Selective angiography of the celiac trunk revealed an arteriovenous-biliary fistula between the proximal branch of the right hepatic artery, the right hepatic vein, and the right biliary system (Figure 3 and Figure 4 ). 


\section{Cureus}

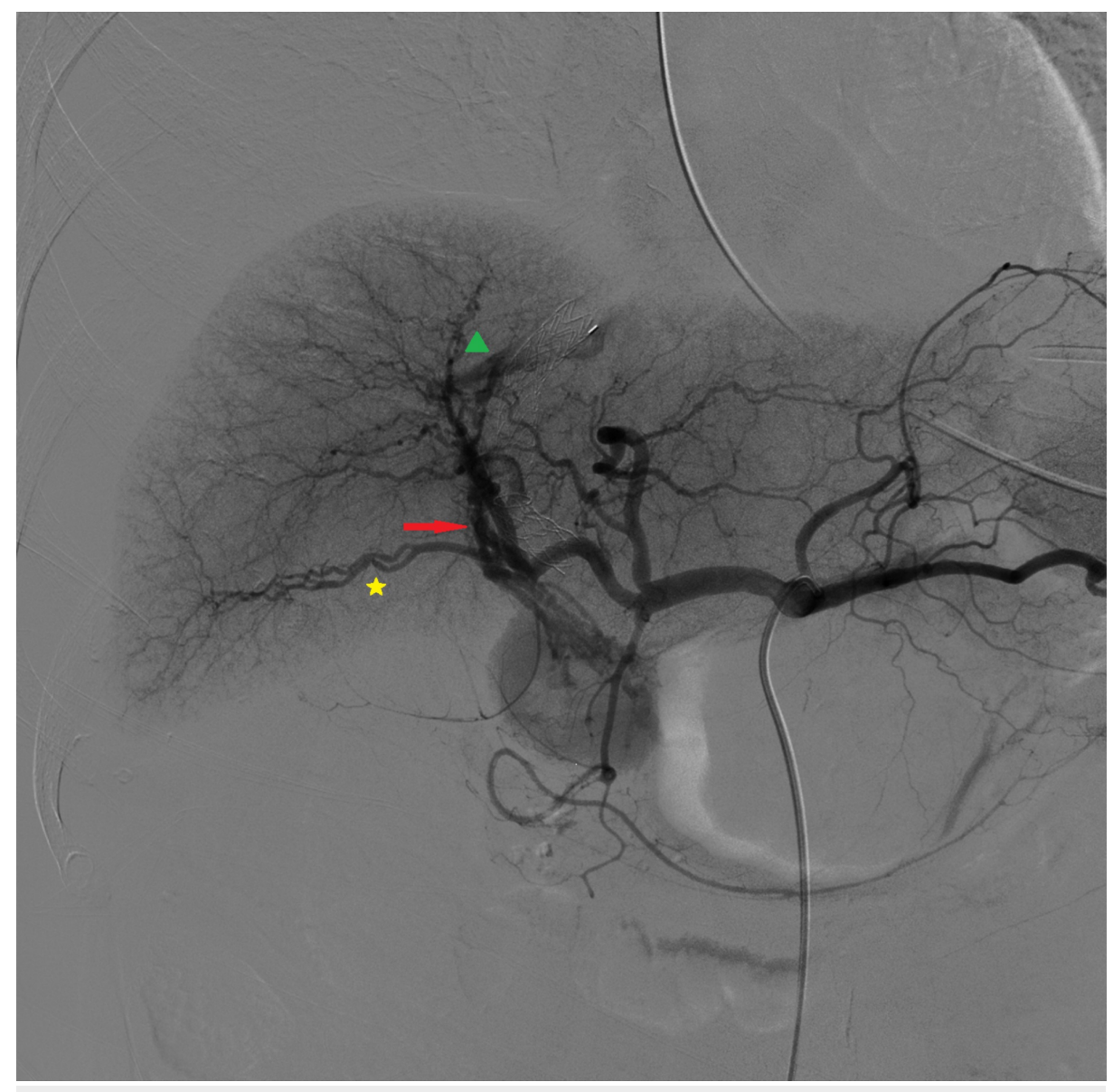

FIGURE 3: Hepatic artery angiography, early phase

Fistula (red arrow) between the proximal branch of the right hepatic artery (yellow star) and the right hepatic vein (green triangle) 


\section{Cureus}

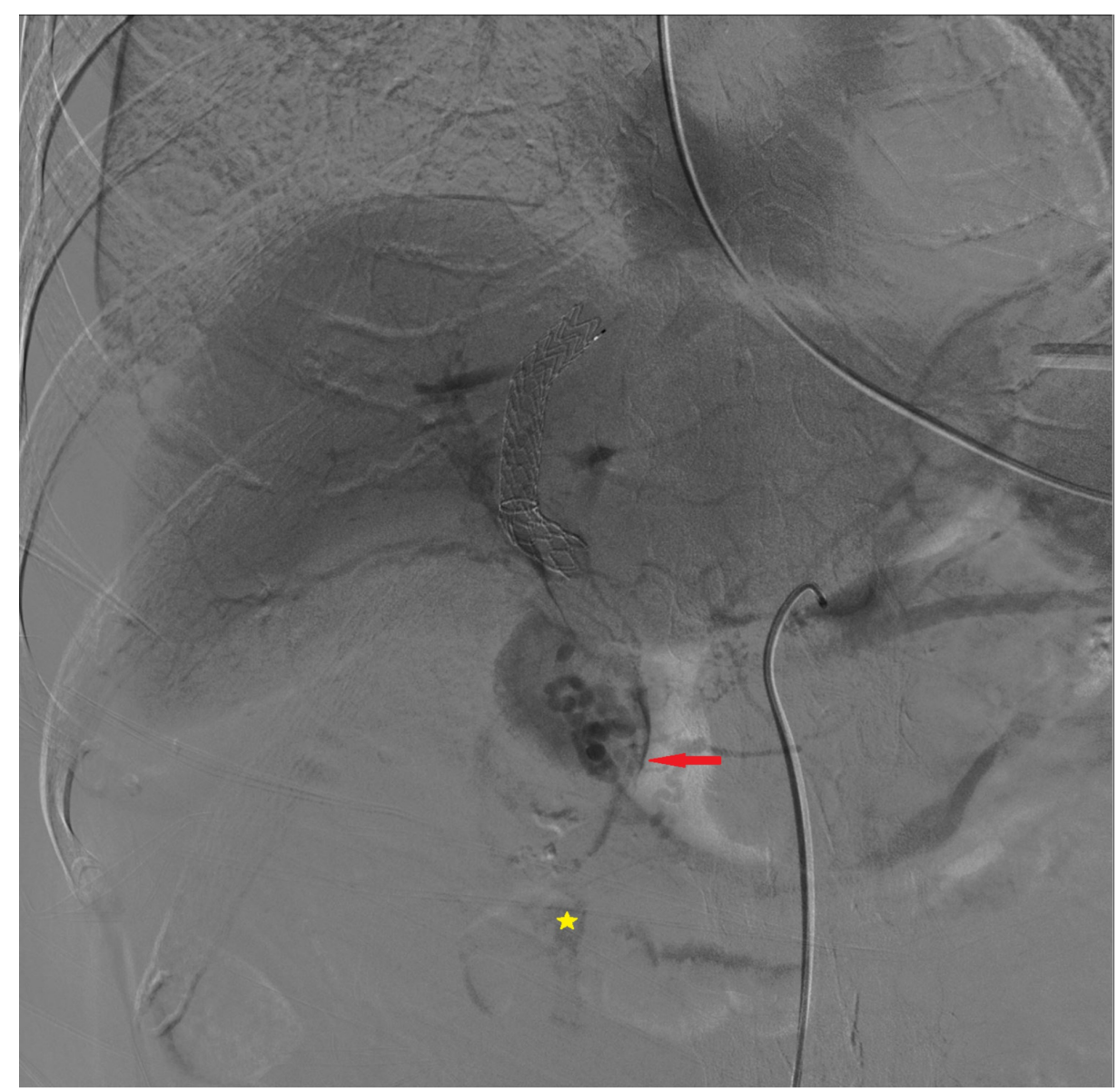

\section{FIGURE 4: Hepatic artery angiography, late phase}

Delayed opacification of the biliary tree (red arrow) and the duodenum (yellow star)

A microcatheter (Progreat 2.7 F; Terumo Corporation, Tokyo, Japan) was advanced within the fistula; contrast media injection confirmed opacification of the hepatic vein, the biliary tree, the choledocus and the duodenum (Figure 5 and Figure 6). 


\section{Cureus}

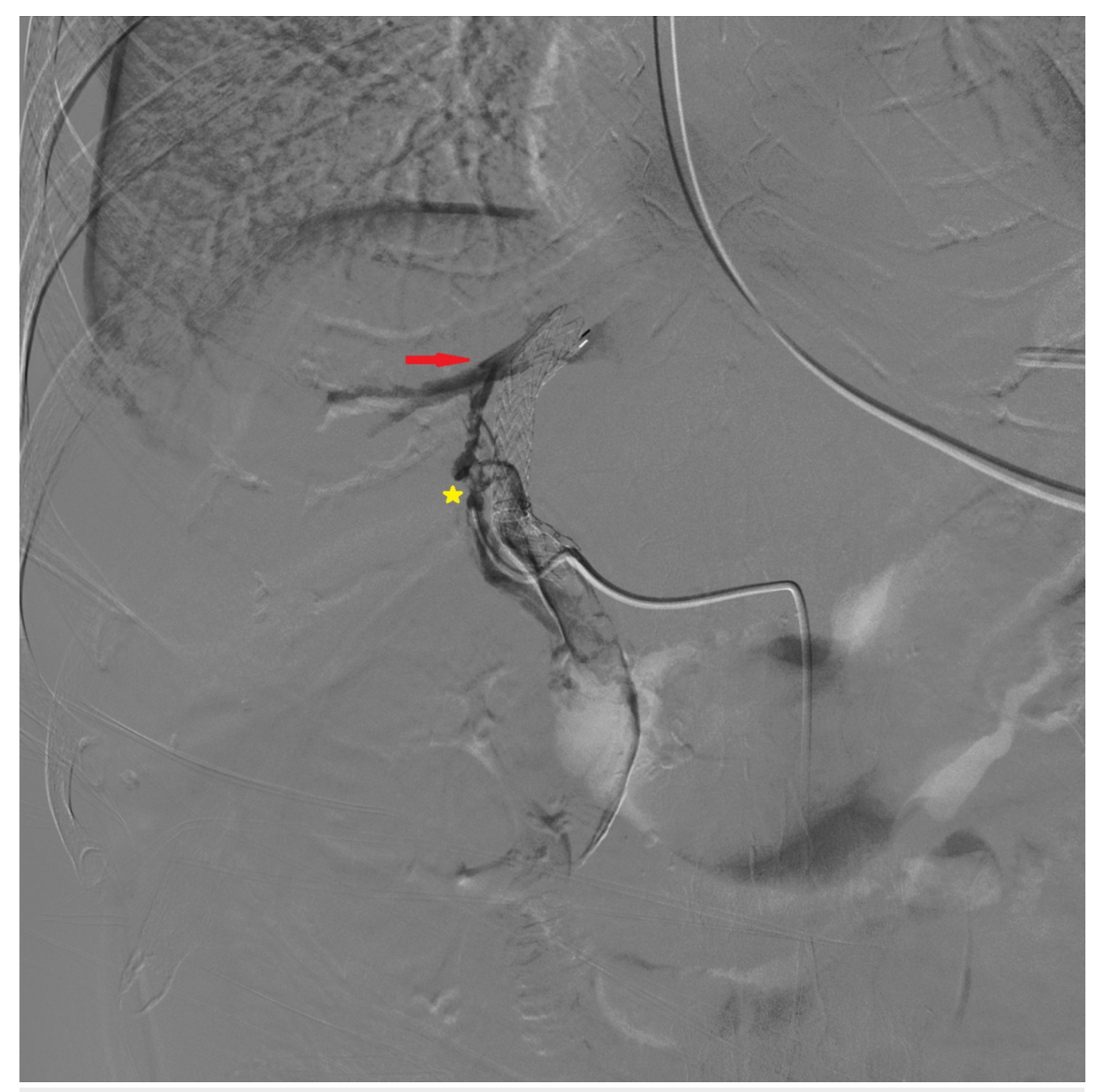

FIGURE 5: Angiography from a microcatheter within the fistula, early phase

Opacification of the hepatic vein (red arrow) and the biliary tree (yellow star) 


\section{Cureus}

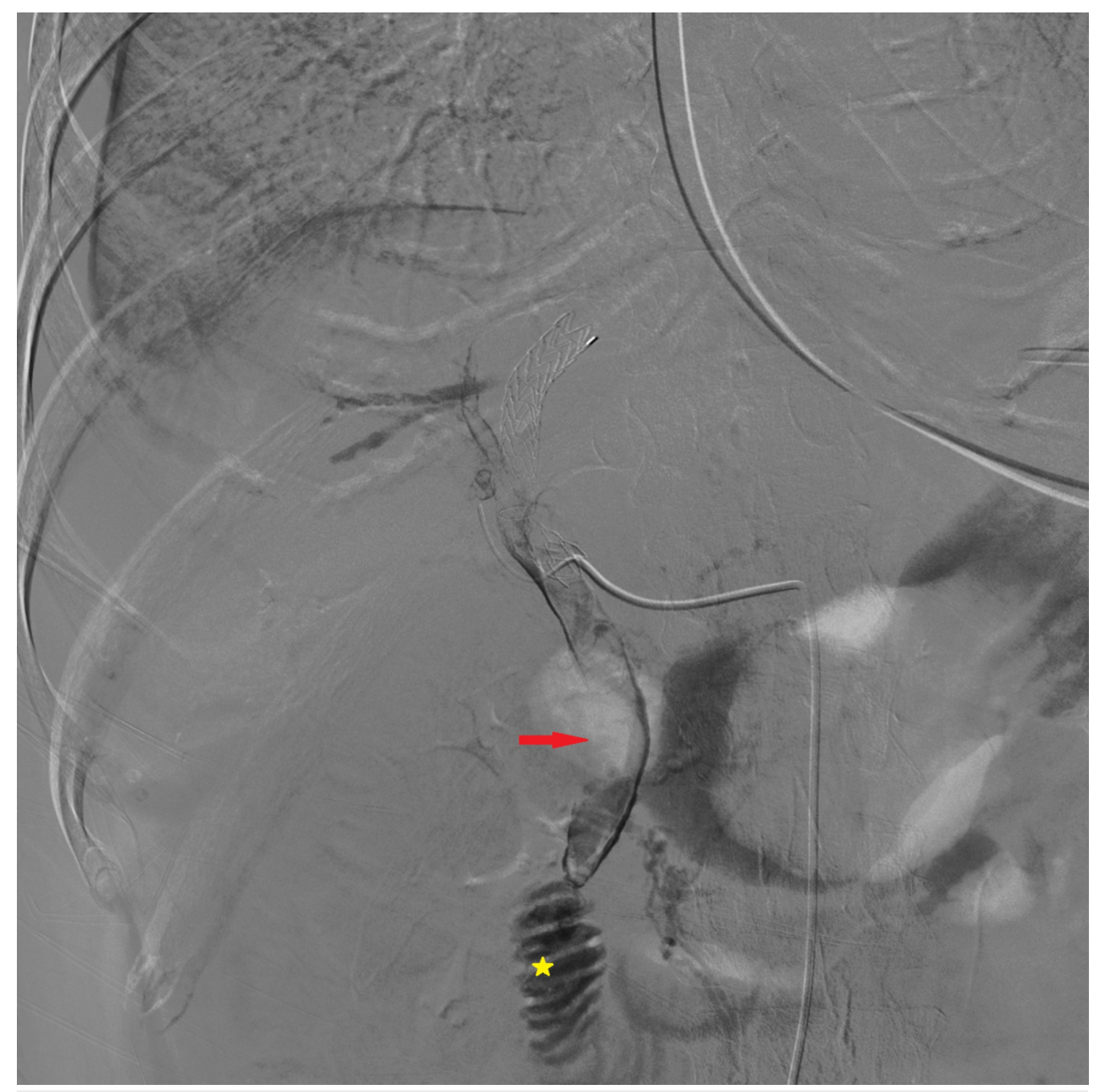

FIGURE 6: Angiography from the microcatheter within the fistula, late phase

Opacification of the choledocus (red arrow) and the duodenum (yellow star)

Pushable microcoils (0.018 Coils; Boston Scientific, Marlborough, Massachusetts) were released inside the fistulous tract (Figure 7). 


\section{Cureus}

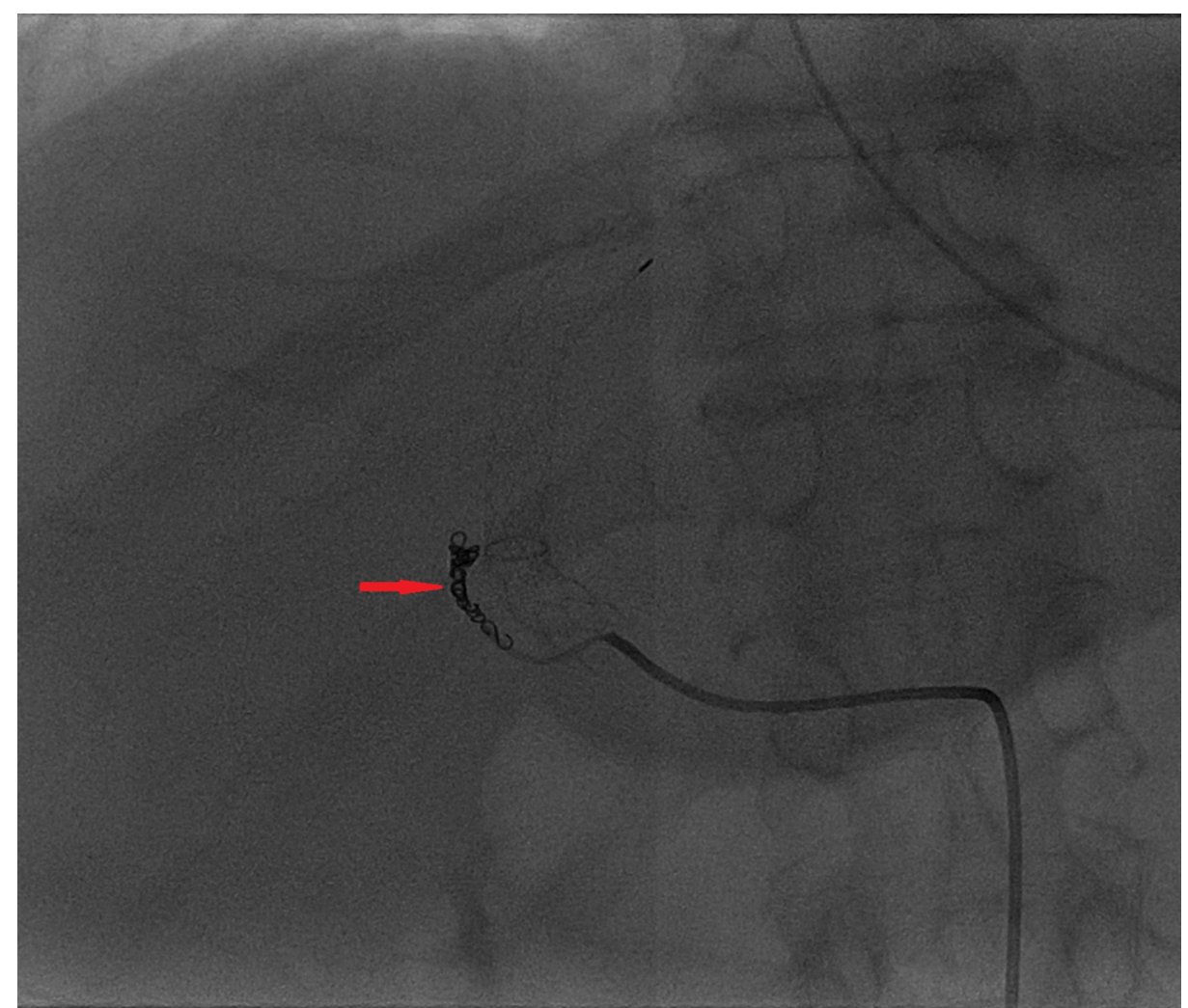

FIGURE 7: Pushable microcoils (red arrow) inside the fistulous tract

Final angiogram demonstrated the exclusion of the hepatic vein and the biliary tract and the patency of the right hepatic artery and its distal branches (Figure 8 ).

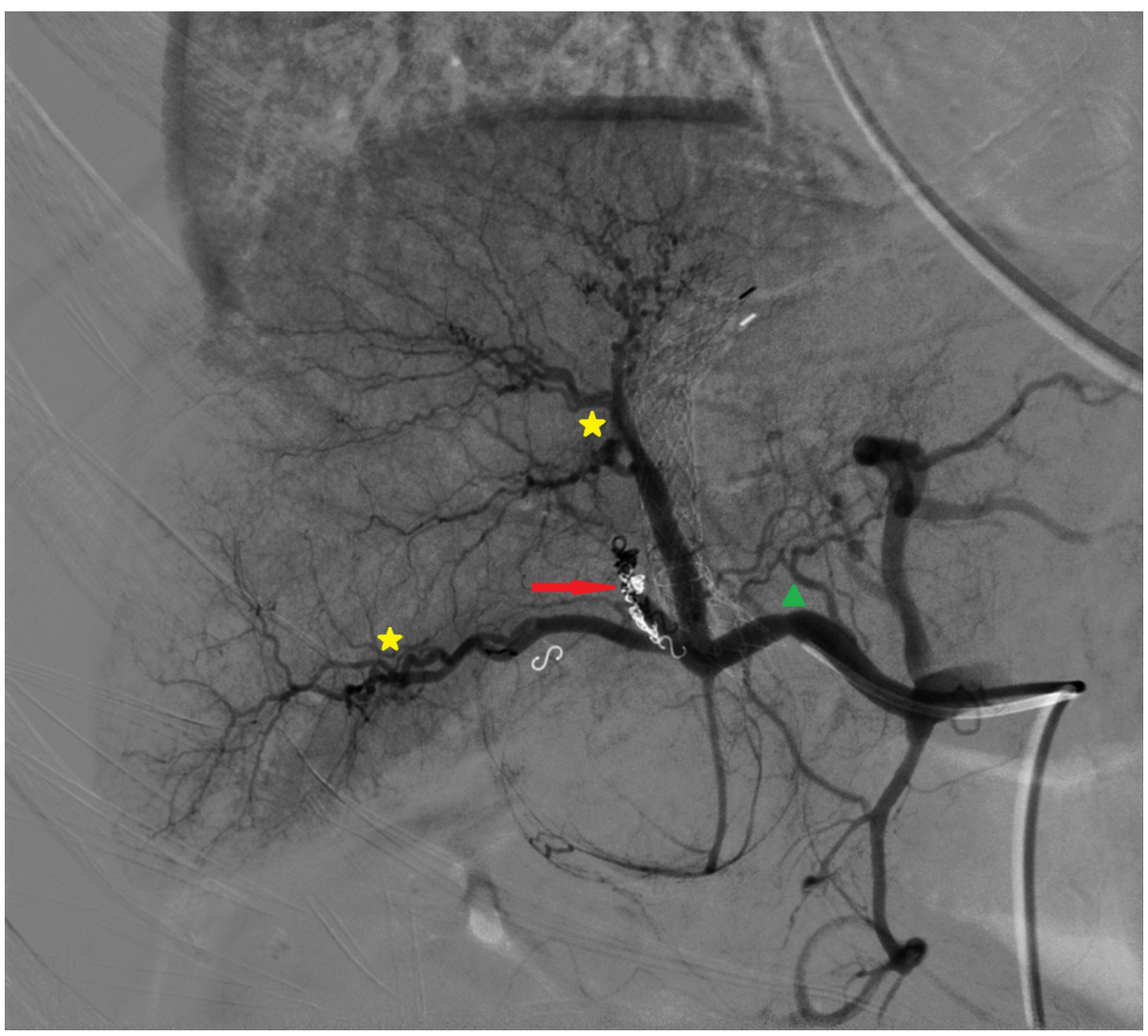

FIGURE 8: Final hepatic artery angiography 


\section{Discussion}

A transjugular intrahepatic portosystemic shunt (TIPS) has been utilized in the treatment of portal hypertensive complications for decades. Indications for TIPS include management of variceal bleeding, refractory cirrhotic ascites, hepatorenal syndrome, gastric antral vascular ectasia, Budd Chiari syndrome, and refractory hepatic hydrothorax [4].

Iatrogenic hemobilia may occur as a result of hepato-biliary procedures. Given the close proximity of bile duct radicals to the branches of the hepatic artery and portal vein, the incidence of concurrent injury to these structures and consequent fistula formation is not unexpected [5-7]. A 3.8\% incidence of hepatic vascular abnormalities was found following percutaneous transhepatic cholangiography, a 5.4\% incidence of hepatic vascular abnormalities following percutaneous liver biopsy, and a $26.2 \%$ incidence following the placement of indwelling transhepatic drainage catheters [8-9]. The frequency of clinical hemobilia ranges from less than $1 \%$ for a liver biopsy to $4 \%$ for transhepatic cholangiography, $3 \%$ to $14 \%$ for percutaneous transhepatic catheter drainage, and $<5 \%$ post-TIPS procedure [10].

Often hemobilia is a self-limiting phenomenon and expectant observation is a commonly used option. Clinically significant hemobilia presents with biliary colic, jaundice, and gastrointestinal bleeding, which may range from occult to massive bleeding.

The initial diagnosis can be made with endoscopy [11]. CT-A is an accurate, cost-effective tool to assess hemobilia and can show the precise location of bleeding, thereby directing further management [12].

Angiography with embolization is the treatment of choice for most cases of hemobilia [13-14]. The goals of therapy in cases of hemobilia are to stop the bleeding and to restore bile flow. Angiography is clearly the most efficacious method for controlling intrahepatic bleeding sources, with success rates above $95 \%$. A complication of embolization includes hepatobiliary necrosis (6\%), abscess formation (9\%), bleeding (6\%), and gallbladder fibrosis (2\%) [15-17].

In this specific case, the bleeding was clinically significant and was a life-threatening event. On the other hand, the therapeutic possibilities were limited by the fact that embolization of the hepatic artery by microparticles or endovascular ligation was highly likely to cause hepatic ischemia also due to the presence of a properly functioning TIPS that stole the portal blood flow. The real therapeutic challenge was to stop the bleeding without interfering with the normal anatomy of the biliary and vascular structures. The only therapeutic possibility was to fill the fistulous tract with spirals without sacrificing arterial branches. The result at the end of the procedure is clearly recognizable by the angiographic images.

\section{Conclusions}

Hemobilia is one of the possible complications of TIPS. A liver parenchymal puncture during a TIPS procedure may damage vascular structures such as the hepatic artery, portal vein, as well as bile duct. In cases of gastrointestinal hemorrhage after TIPS placement, a suspicion of hemobilia should be high. After the diagnosis of hemobilia is confirmed by upper endoscopy or CT-A, transcatheter embolization is the gold standard in the management of hemobilia.

\section{Additional Information}

\section{Disclosures}

Human subjects: Consent was obtained by all participants in this study. Conflicts of interest: In compliance with the ICMJE uniform disclosure form, all authors declare the following: Payment/services info: All authors have declared that no financial support was received from any organization for the submitted work. Financial relationships: All authors have declared that they have no financial relationships at present or within the previous three years with any organizations that might have an interest in the submitted work. Other relationships: All authors have declared that there are no other relationships or activities that could appear to have influenced the submitted work.

\section{References}

1. Cathcart S, Birk JW, Tadros M, Schuster M: Hemobilia. An uncommon but notable cause of upper gastrointestinal bleeding. J Clin Gastroenterol. 2017, 51:796-804. 10.1097/MCG.0000000000000876

2. van der Velden APS, de Ruijter WM, Janssen CM, Schultze Kool LJ, Tan EC: Hemobilia as a late complication after blunt abdominal trauma: a case report and review of the literature. J Emerg Med. 2010, 39:592-595. 10.1016/j.jemermed.2008.08.015

3. Richard J, Thornburg B: New techniques and devices in transjugular intrahepatic portosystemic shunt 
placement. Semin Intervent Radiol. 2018, 35:206-214. 10.1055/s-0038-1660800

4. Rosch J, Keller FS: Transjugular intrahepatic portosystemic shunt: present status, comparison with endoscopic therapy and shunt surgery, and future prospectives. World J Surg. 2001, 25:337-345. $10.1007 /$ s002680020380

5. Okuda K, Musha H, Nakajima Y, Takayasu K, Suzuki Y, Morita M, Yamasaki T: Frequency of intrahepatic arteriovenous fistula as a sequela to percutaneous needle puncture of the liver. Gastroenterology. 1978, 74:1204-1207. 10.1016/0016-5085(78)90693-5

6. Sandblom P: Iatrogenic hemobilia. Am J Surg. 1986, 151:754-758. 10.1016/0002-9610(86)90059-0

7. Zhornitskiy A, Berry R, Han JY, Tabibian JH: Hemobilia: historical overview, clinical update, and current practices. Liver Int. 2019, 39:1378-1388. 10.1111/liv.14111

8. Cahow CE, Burrell M, Greco R: Hemobilia following percutaneous transhepatic cholangiography. Ann Surg. 1977, 185:235-241. 10.1097/00000658-197702000-00019

9. Merrell SW, Schnerder PD: Hemobilia-evolution of current diagnosis and treatment. West J Med. 1991, 155:621-625.

10. Boyer TD, Haskal ZJ: The role of transjugular intrahepatic portosystemic shunt in the management of portal hypertension. Hepatology. 2005, 41:386-400. 10.1002/hep.20559

11. Navuluri R: Hemobilia. Semin Intervent Radiol. 2016, 33:324-331. 10.1055/s-0036-1592321

12. Wu LM, Xu JR, Yin Y, Qu XH: Usefulness of CT angiography in diagnosing acute gastrointestinal bleeding: a meta-analysis. World J Gastroenterol. 2010, 16:3957-3963. 10.3748/wjg.v16.i31.3957

13. Srivastava DN, Sharma S, Pal S, et al.: Transcatheter arterial embolization in the management of hemobilia . Abdom Imaging. 2006, 31:439-448. 10.1007/s00261-005-0392-7

14. Stefanczyk L, Polguj M, Szubert W, Chrzastek J, Juralowicz P, Garcarek J: Arterio-biliary fistulas: what to choose as endovascular treatment?. Vascular. 2018, 26:445-448. 10.1177/1708538117743178

15. Kaswala D, Gandhi D, Moroianu A, Patel J, Patel N, Klyde D, Brelvi Z: Hemobilia secondary to transjugular intrahepatic portosystemic shunt procedure: a case report. J Clin Med. 2012, 1:15-21. 10.3390/jcm1010015

16. Yin X, Lei X, Xu C, Yang J, Zhao Y, Li K: Hepatic artery embolization cures the acute pancreatitis associated with a tiny arteriobiliary fistula after TIPS. A case report. Medicine (Baltimore). 2017, 96:e9267. 10.1097/MD.0000000000009267

17. Corral JE, Mousa OY, Riegert-Johnson DL: Massive gastrointestinal bleeding after transjugular intrahepatic portosystemic shunt (TIPS). Gut. 2018, 67:1123. 10.1136/gutjnl-2017-314254 